\title{
Trabalho docente e organização sindical em Minas Gerais
}

\section{Teachers' labor and the unionism in Minas Gerais}

\author{
Savana Diniz Gomes Melo ${ }^{1}$
}

\begin{abstract}
RESUMO
O artigo, que é fruto de pesquisa em andamento, reúne ideias sobre o trabalho e a organização sindical dos docentes da educação básica pública. Procura destacar a complexidade que envolve tais aspectos, sobretudo nos últimos anos, como fruto das transformações ocorridas na organização escolar e na organização do trabalho escolar, em decorrência das grandes transformações processadas na sociedade, nas últimas décadas. Toma como objeto para análise as redes públicas de ensino e organizações sindicais que representam seus docentes na capital do estado de Minas Gerais. São evidenciados aspectos mais relevantes do trabalho realizado nessas redes, da história das organizações sindicais e suas características atuais, assim como as tensões e desafios enfrentados nos últimos anos. O estudo é pautado em documentos produzidos pelas organizações de sindicatos (boletins, jornais, informes, entre outros, preferencialmente disponibilizados nos respectivos sites) e, ainda, em entrevistas semiestruturadas, realizadas com dirigentes dessas organizações, em 2010. A partir dos resultados obtidos até o presente momento, constata-se que há significativas convergências e divergências entre as organizações sindicais, o que se evidencia em algumas variáveis, tais como: abrangência da organização; estrutura e organização; ações desenvolvidas; reivindicações; dificuldades e desafios enfrentados; entre outras.
\end{abstract}

Palavras-chave: sindicalismo docente; trabalho docente.

${ }^{1}$ Doutora em Educação pela Universidade Federal de Minas Gerais (UFMG). Professora da Faculdade de Educação da UFMG e do Programa de Pós-Graduação em Educação. Investigadora do Grupo de Pesquisa Política Educacional e Trabalho Docente (GESTRADO), da Rede Latino-americana de Estudos sobre Trabajo Docente (REDE ESTRADO) e integrante da Coordenação Colegiada da Rede de Pesquisadores sobre Associativismo e Sindicalismo dos Trabalhadores em Educação (REDE ASTE), Brasil. E-mail: sdgmufmg@gmail.com. 


\begin{abstract}
This article, which is the result from a research in course, meets ideas about the teachers' labor and the teachers' unionism in the elementary public school. It aims at highlighting the complexity that involves those aspects, mostly in the last years, as a result from transformations in the schools organization and in their work form of organization which occurred in society in the last decades. It takes as object to analyze public education systems and trade union organizations that represent their teachers in Minas Gerais State capital city. The most relevant aspects of work done in those systems are shown, as well as the trade unions organization history and their current characteristics, and also the tensions and challenges faced in the last years. This study is built on documents produced by union entities (bulletins, newspapers, reports, among others, preferentially published in their websites) and, still, on semistructured interviews made with union leaders in 2010. From the results obtained until now, it is possible to observe significant convergences and divergences among the trade unions, as it is evident in some variables, such as: organization scope; structure and organization; actions developed; claims, difficulties and challenges, among others.
\end{abstract}

Keywords: teachers unionism; teachers' labor.

\title{
Apresentação
}

Este estudo é fruto de pesquisa em curso sobre a resistência e a organização sindical dos docentes da educação básica pública em Minas Gerais². Toma como objeto de análise o Sindicato Único dos Trabalhadores em Educação de Minas Gerais (Sind-UTE/MG) e o Sindicato dos Trabalhadores em Educação da Rede Pública Municipal de Belo Horizonte (Sind-rede/BH), que representam docentes das redes públicas de ensino da Rede Estadual de Ensino de Minas Gerais (REE/MG) e da Rede Municipal de Ensino de Belo Horizonte (RME/ $\mathrm{BH})$. A primeira seção do texto busca caracterizar os sindicatos estudados e promover uma breve comparação entre eles, considerando algumas variáveis obtidas em fontes documentais, entrevistas e depoimentos de seus dirigentes. A segunda se dedica a apresentar as perspectivas dos sindicatos docentes, em

${ }^{2}$ A Pesquisa é vinculada ao Grupo de Pesquisa Gestrado/UFMG e conta com a colaboração dos graduandos de pedagogia Rodolfo Vinícius Amorim César, Luciana Cristina Nogueira H. Rodrigues, Camila Raquel Benevenuto e Ana Carla Bernardes Silva. 
relação às políticas estatais para a educação e o trabalho docente. As fontes de informação foram publicações dos próprios sindicatos (Boletins, documentos, artigos de revistas, textos divulgados em seus sites, entre outros) que expressassem seus argumentos e percepções acerca das políticas empreendidas no período de 2004-2010.

\section{Caracterização dos sindicatos docentes mineiros estudados}

O Sind-UTE/MG, criado em 1979, tem por finalidade representar, coordenar e defender os interesses da categoria dos trabalhadores em Educação Pública estadual e municipal de Minas Gerais, da educação básica (dos níveis infantil, fundamental e médio), bem como os trabalhadores dos órgãos da Secretaria de Estado da Educação de Minas Gerais, central e regionais, das fundações, autarquias e da Secretaria de Desenvolvimento Social, assim compreendidos os professores, pedagogos, diretores, auxiliares de serviço, auxiliares administrativos e técnicos em educação.

O Sind-rede/BH, fundado em 2007, tem sua história iniciada em 2006, com uma divisão no Sind-UTE/MG, quando a categoria de trabalhadores em Educação de Belo Horizonte aprovou sua fundação com o objetivo de criar um "sindicato independente de governos, classista, de luta e combativo", já que, na percepção dos seus fundadores, aquele se encontrava atrelado ao PT, partido que ocupava o governo federal. A disputa interna engendrou a autonomização da subsede de Belo Horizonte e o novo sindicato foi criado. A fundação do Sind-rede/BH prontamente acarretou consequências tais como o acirramento do antagonismo com o governo da Prefeitura de Belo Horizonte (PBH), na gestão de Patrus, do PT; a negação do Ministério do Trabalho em conceder a Carta Sindical à organização recém-criada, e a suspensão do repasse da contribuição dos filiados pela $\mathrm{PBH}$, realizado mediante o desconto em folha. A solução encontrada pela diretoria do novo sindicato foi a adoção de desconto através de débito, o que contou com o apoio de organizações aliadas e, em especial, da categoria para manter seus rendimentos, sem depender financeira e administrativamente da $\mathrm{PBH}$.

O Sind-UTE/MG representa trabalhadores em educação que atuam na Rede Estadual de Educação de Minas Gerais (REEMG) e também em algumas redes públicas municipais do interior do estado que não possuem sindicato próprio. Tal configuração implica maior complexidade em termos de organização e proximidade com a base, sobretudo em um Estado que possui 853 municípios, que é 
o caso de Minas Gerais. O Sind-rede/BH representa trabalhadores em educação que atuam na RME/BH, como já referido. Em ambos, o maior contingente de filiados é constituído por professores.

Enquanto o Sind-rede/BH é circunscrito à capital mineira, o Sind-UTE/MG tem abrangência estadual, com subsedes no interior do Estado. Sua organização atual é descentralizada, com mais de 80 subsedes, abarcando mais de 440 do total de 853 municípios mineiros. As subsedes gozam de autonomia política e administrativa na condução de suas tarefas, possuem direção própria e congregam ou representam um conjunto de municípios e podem apresentar reivindicações específicas, além daquelas gerais anunciadas para o conjunto da REE/MG. A organização local e a condução são praticadas nos próprios municípios.

Em 2010, o Sind-UTE/MG contava com 83 mil filiados em um universo de 398 mil trabalhadores ativos e aposentados. Sua base heterogênea em termos de vínculo trabalhista compunha-se de efetivos, efetivados e designados. Esses últimos alcançavam a marca de $40 \%$ do total de trabalhadores do estado ${ }^{3}$.

O Sind-rede/BH informava possuir, no mesmo ano, 4.411 filiados em um universo de 13.000 trabalhadores. Desse total, $80 \%$ eram de docentes. Como na RME/BH não havia contratação de professores temporários, sua base era mais homogênea em termos de vínculos trabalhistas. Contudo, nos últimos anos, vem ocorrendo um processo de privatização, que se expressava pela via da Caixa Escolar, mediante a contratação de mais 70 auxiliares de escola, precariamente, fora do quadro e que por essa razão não podiam ser representados formalmente pelo sindicato, embora lhes viesse sendo dado apoio e orientação. Outra forma de privatização se dava pela via de onerosas parcerias, a exemplo do Projeto Floração, desenvolvido com a Fundação Roberto Marinho, e que oferece um misto de educação a distância e presencial para certificação de crianças do ensino fundamental.

Enquanto o Sind-UTE/MG é filiado à Confederação Nacional dos Trabalhadores em Educação (CNTE) e à Central Única dos Trabalhadores (CUT), o Sind-rede/BH se integra à Central Sindical Popular (CSP-CONLUTAS).

Nos dois sindicatos reivindica-se a sua autonomia política, mas seus dirigentes afirmaram filiar-se e/ou desenvolver relações muito próximas a partidos políticos. Diretores do Sind-UTE/MG eram filiados ou tinham aproximação com o Partido dos Trabalhadores (PT). No Sind-rede/BH a filiação ou proximidade de diretores se dava com o Partido Socialista dos Trabalhadores Unificado (PSTU), que foi o seu principal organizador.

${ }^{3}$ Os efetivados são amparados pela Lei Complementar $n^{\circ} 100$, de 2007, adquirem o direito previdenciário, mas não têm estabilidade. Os designados são os contratados temporários no período do ano escolar, com amparo no inciso IX do artigo 37, da Constituição Federal: "contratação por tempo determinado para atender a necessidade temporária de excepcional interesse público". 
Quanto à forma de organização interna dos sindicatos, verificou-se que ambos possuíam direção colegiada, o que, em tese, indica uma tendência de adoção de relações de poder mais horizontais, e pode favorecer o estabelecimento de relações democráticas no interior da organização, mas que necessitaria de confirmação pela prática social cotidiana dessas organizações. A direção do Sind-UTE é constituída por 54 membros, sendo 38 diretores regionais e 16 metropolitanos, distribuídos em departamentos. O sindicato conta com aproximadamente 80 subsedes distribuídas pelo Estado. São suas instâncias deliberativas o Conselho Estadual, o Conselho Geral, a Diretoria Geral e o Conselho Fiscal. A diretoria do Sind-rede/BH é composta por 30 integrantes, todos profissionais da educação municipal, com o mandato de três anos. A composição da diretoria é proporcional ao número de votos de cada chapa, cujos diretores eleitos e empossados se distribuem em departamentos. Acima da Diretoria situa-se a Plenária de Representantes de Escolas. Tais representantes são eleitos nas escolas, por turno, visando favorecer a representação, a relação e o encaminhamento das demandas ao sindicato nos locais de trabalho. Estatutariamente, a Plenária de Representantes é superior à Diretoria, mas na prática, nem sempre isso ocorre.

No que tange a relação e interação com a base, verificaram-se estratégias comuns e algumas diferenças. Uma generalidade é que ambos os sindicatos pesquisados possuíam site e utilizavam a internet como importante meio de informação, divulgação, correspondência e pesquisa da organização. Outra é que os dois informaram receber individualmente os filiados na sede da organização, para o que contavam com estrutura própria para atendimento. Eventos coletivos tais como assembleias, congressos e reuniões com a base eram realizados por ambos. Enquanto a direção do Sind-UTE/MG se aproximava mais das direções das regionais, o Sind-rede/BH contava com a Plenária de Representantes de Escola, que a aproximava mais dos locais de trabalho.

Os dois sindicatos possuíam como principal fonte de financiamento as cotas de seus agremiados, no valor mensal fixo de $1 \%$ do salário dos sindicalizados. Ambos possuem sede própria situada na capital mineira.

As demandas dos filiados aos sindicatos em geral são variadas, mas nas organizações pesquisadas a maior parte delas referia-se aos serviços de assistência jurídica. No Sind-UTE/MG, se buscava a mediação em aposentadorias, enquanto no Sind-rede/BH, sobressaíam os juízos relativos a perdas de direito imputadas aos trabalhadores pela administração municipal. Em ambos os sindicatos havia um expressivo aparato jurídico, em geral com oferta de plantões de atendimento aos filiados, já que a procura é muito grande. Isso denota que muitos dos objetos de conflito no campo da educação são tratados e deliberados pela área judicial, em detrimento da via política. Em caso de ações coletivas vitoriosas, que em geral levam anos para o desfecho, um percentual sobre os ganhos dos trabalha- 
dores é devido ao sindicato, o que, também, constitui uma significativa fonte de rendimentos das organizações que, entretanto, é de difícil captura.

Embora os dirigentes dos sindicatos pesquisados tenham afirmado reconhecer a importância da realização de atividade de formação política junto aos associados, nenhum dos sindicatos realizava atividade sistemática de formação política dirigida aos associados. O Sind-rede/BH desenvolvia esse tipo de formação voltada aos diretores do sindicato. No caso do Sind-UTE, a greve foi considerada o principal instrumento de formação política da organização. Os argumentos justificadores da falta ou insuficiência de formação política foram a ausência de tempo dos trabalhadores filiados, inexistência de espaços nas escolas e falta de condições por parte da própria organização para essa oferta. Além da comunicação e informação da base, ambos os sindicatos buscam manter publicações periódicas, de caráter formativo.

Os principais desafios apontados por dirigentes de ambos os sindicatos foram comuns: organizar a base, aumentar a filiação, conseguir melhores condições de trabalho e salários dignos para a categoria. Destaca-se, ainda, a obtenção de reconhecimento da importância da profissão docente e da necessidade de revalorizá-la. O Sind-rede/BH apontou ainda a participação dos representantes de escola nas reuniões e ações empreendidas pela diretoria e o desafio das entidades sindicais em compreender e fazer com que os trabalhadores ou parte deles compreendam o projeto da classe dominante para a educação pública. Destaca-se a posição de oposição frontal à atual política dos governos (municipal, estadual e federal), o que se relaciona com sua vinculação à CSP-CONLUTAS, organização de escopo mais amplo que uma central sindical nos moldes tradicionais, colocando o sindicato ao lado dos que procuram promover a reorganização da classe trabalhadora e, para tanto, buscando construir-se como uma alternativa para as lutas dos trabalhadores.

Após essa breve visão panorâmica dos sindicatos, serão apresentadas as suas perspectivas sobre a política educativa e o trabalho docente.

\section{Perspectivas dos sindicatos}

Convém lembrar, inicialmente, que os sindicatos estudados formavam uma única organização sindical e, somente a partir de 2007, com a autonomização da subsede de Belo Horizonte, conformam-se duas organizações. Essa mudança deve orientar a leitura das evidências recolhidas nas publicações dessas organizações, que em seu conjunto abordam uma variedade de temas. 
Ao longo do período estudado o Sind-UTE/MG apresenta uma série de publicações com objetivos e periodicidades distintos. São eles: Boletim (BO), Informe (IN), Conselho Geral (CG), Outras Palavras (OP), Subsedes (SUB), Departamentos (DEP), Outros (OT). No conjunto dessas fontes totalizaram-se 114 documentos.

O Sind-rede/BH, como sindicato recém-criado, busca efetivar sua organização sob bases novas e consolidar-se junto a seus representados e ao governo municipal. No período de 2007 a 2010, suas principais publicações possuíam objetivos, formato e periodicidades distintos. Entre elas se destacam o Boletim da Rede (BR), o Jornal da Rede (JR), os Informativos Especiais dos Sind-rede/ BH (ER), o Boletim da Greve e outros documentos sobre o tema (BG), bem como documentos avulsos, sem nominação e/ou datas explicitadas (DA), como informes sobre campanha salarial e pautas de reivindicações, por exemplo. Há publicações mais densas e elaboradas, dedicadas a temas específicos, como os Cadernos de Formação do Sind-rede/BH (CF) e as Cartilhas (CAR). As publicações do Sind-rede/BH são inicialmente de menor expressão numérica, mas vão se avolumando e qualificando com o passar dos anos. Ao todo foram estudados 35 documentos no período de 2007 a 2010.

Os principais temas identificados nas publicações de ambos os sindicatos foram sintetizados em 11 eixos: 1. Salarial, 2. Profissional, 3. Seguridade Social, 4. Saúde, 5. Relações de Emprego, 6. Condições de Trabalho, 7. Organização e Relações Sindicais, 8. Gestão da Escola, 9. Política Educacional, 10. Justiça Social, 11. Manifestações de Conflito. Algumas evidências do tratamento de tais temas serão apresentadas em seguida.

\section{Salarial}

Nas publicações do Sind-UTE/MG a questão salarial é tratada em matérias referentes a: "discussão do plano de carreira", "incorporação de abonos", "pagamento pontual de salários", "recepção de salários e benefícios", "recibo de pagos e benefícios atrasados ou retidos devido à greve"; "pagamento total de férias e o $13^{\circ}$ salário" (IN 06, 12/2004; BO 12/2006) e ainda discussões de "tabelas ou pedidos de reajuste salarial" e "recomposição de perdas salariais" (PCG 0304/2004; BO 2/2004; BO 6,8,9A e B/2005; BO 12,14/2006; OP 49/2006; BO $01,05)$. Chama a atenção como vai ganhando corpo nas publicações a partir de 2007 o tema do "piso salarial profissional nacional (PSPN)" (BO 6/2007; IN 08, 09, 10, 11, 12/2007). Sem dúvida, nas notas publicadas a partir de 2009, a maior parte dos títulos se dirigiam a esclarecer os trabalhadores sobre o projeto de Lei de PSPN; a resposta sobre o valor anunciado pelo Ministério da Educação e a apresentação da proposta da CNTE (BO 02, 05, 06/2007). Muitos títulos 
se dedicam à "Campanha de Mobilização pelo Piso" e tratam de convocar os trabalhadores a participar (IN 02, 04 /2010). Outros tratam da "implementação do PSPN" (BO 12/2008; BO 03/2009) e da busca de "sua efetivação no estado de Minas Gerais" (BO 7, 09/2007; IN 03, 05/2007). O título "Sind-UTE/MG inaugura manifestações na Cidade Administrativa" anuncia [...] um grande ato de inauguração da Cidade Administrativa de Minas. Na ocasião, lutaremos pela implantação do PSPN". No corpo do texto se esclarece que o conjunto arquitetônico cumpre a função de "projetar nacionalmente o Governador Aécio Neves em um ano eleitoral". Denuncia-se que a imprensa não divulga o real valor da Cidade, que custou em torno de $\mathrm{R} \$ 1,6$ bilhões e que parte significativa da construção nos terrenos da Cidade Administrativa está sendo questionada judicialmente. O texto destaca que obras "faraônicas estão sendo edificadas pelo governo de Minas", enquanto "a educação é relegada a planos inferiores" (IN 05/2010). Destaca-se a presença de títulos que tratam da "mudança no padrão remuneratório dos servidores da educação". Isso se expressa no título "Atuação do Sind-UTE/MG na comissão" que assumiu a responsabilidade por discutir e propor a modificação dos vencimentos básicos e o padrão remuneratório proposto. O documento apresenta e esclarece as propostas do governo que incluem o pagamento da remuneração por subsídio: "O que o governo propõe com a remuneração por subsídio" (BI 14, de 17/06/2010). O novo padrão se implantava implicando em perdas salariais ${ }^{4}$ aos trabalhadores que, ainda hoje, lutam pelo cumprimento da Lei do PSPN no Estado.

Nas publicações do Sind-rede/BH o tema é tratado em várias matérias: a "recomposição de perdas", "reajuste", "aumento do valor do cartão-alimentação", "extensão deste direito para todos/todas", "garantia de lei de reajuste para celetistas" (BR 02/2007; BR 11/2009, JR n 24, 06/2010); "incorporação de todas as gratificações e bonificações aos salários e sua extensão aos aposentados" (BR 03/2008); "criação de um indexador para proteger o salário contra perda", "pagamento do salário no último dia útil do mês", "pagamento de quinquênios em dia" (DA, 2009); "corte do vale-alimentação das educadoras infantis" (BR 10/08/2009). O tema salarial também aparece como preocupação apontada inclusive pelos auxiliares de biblioteca, secretaria e de escola (BR 05/2009).

${ }^{4}$ A implementação do subsídio implicou perdas como: extinção de aportes nominais pagos por complementos salariais e vantagens para os servidores da educação; redução de percentuais de promoção e progressão nas tabelas salariais dos educadores, que caíram de $10 \%$ para $2,5 \%$ respectivamente, contra $22 \%$ e $3 \%$ de antiguidade no regime remuneratório; "confisco" do tempo de serviço de praticamente todos os servidores, que foram reposicionados no grupo inicial da tabela de subsídios. 


\section{Profissional}

No Sind-UTE/MG o tema emerge em matérias sobre campanhas salariais, como reivindicações relativas à "discussão do plano de carreira" (IN 09, 11, EE 10/2004, OP 48/2006). Outras tratam de "concessão de adicionais" como biênios ou quinquênios e reposicionamentos por tempo de serviço (IN 06, 07/2007). Há matérias sobre a necessidade de observar o PSPN estabelecido pelo CNE e outras dedicadas à discussão da Declaração Internacional da Educação sobre ética da profissão (OP 48/2006). Outras abordam a formação dos trabalhadores com textos formativos ou que fazem referências a eventos realizados ou apoiados pelo sindicato. Entre os textos destacam-se entrevistas como "Vida e obra de Paulo Freire" e "Situação da escola e do educador" (OP 49/2006) ou artigos como "Formação inicial e contínua dos profissionais da educação" (IN 03/2006), período em que o sindicato ainda era integrado pela subsede de Belo Horizonte. Alguns textos tratam da formação oferecida pelo sistema de ensino, tais como o "Projeto Profuncionario", que oferece cursos de capacitação para funcionários das áreas de "alimentação nas escolas" e "gestão das escolas" (BO 05/2009). Entre os eventos registra-se a "Semana Paulo Freire" (BO 10/2006). A partir de 2007 destacam-se o seminário "Reforma Política no Brasil" (BO 02/2007); o curso de "Formação de dirigentes" (BO 02/2007). Observa-se, a partir do governo de Aécio Neves, o claro deslocamento da atenção do sindicato para questões postas pelos Programas "Choque de Gestão" e "Estado para Resultados" empreendidos pelo governo estadual.

No Sind-rede/BH há matérias que ao abordarem campanhas salariais também trazem temas como reivindicações relativas a: "discussão do plano de carreira" e "formação" (BR 02/2007). Observam-se notícias que repudiam a Lei no 9815/2010 que trata da "política de abono" (DA, [20--]). Há os que reivindicam "isonomia salarial entre professores estatutários e celetistas, entre educadores infantis e os professores estatutários e entre os servidores que possuem cargo superior" e de "unificação das carreiras dos educadores infantis e dos professores municipais" (BR 02/2007, JR n ${ }^{\circ} 24,06 / 2010$, BR 11/2010, JR $\left.\mathrm{n}^{\mathrm{o}} 26,12 / 2010\right)$. Outras tratam do "enquadramento por tempo de serviço real e formação", e "progressão imediata dos que possuem o direito" (BR 02/2007).

\section{Seguridade Social}

No Sind-UTE/MG se observam notícias tais como a "defesa do Instituto Municipal de Aposentados"; reivindicações pela não "alteração de regras de pensão e aposentadoria por invalidez"; "avaliação de projetos de lei sobre seguridade social" (BO 10/2007; IN 14/2007); "pensões por acidente e morte" e "contra a retirada do direito à aposentadoria de professores" (SUB 90/2005). 
No Sind-rede/BH as notícias expressam posições "contra a extinção da BEPREM", a defesa do "patrimônio da BEPREM para o Fundo de Previdência Municipal"; e reivindicações por "transparência na contabilidade da Previdência Municipal" (BR 02/2007, JR nº 24, 06/2010). Algumas matérias apresentam informes sobre a tramitação e o conteúdo de propostas de legislação, como é o caso do título "Previdência: a situação atual do PL 1920" (BR 11/2010). Outras divulgam ou debatem resultados de eventos sobre o tema, tal como o "Seminário Saúde e Previdência" (BR 11/2010, JR n²6, 12/2010).

\section{Saúde}

No Sind-UTE/MG se encontram títulos que expressam a demanda formalizada de "melhoria da qualidade e ampliação da rede conveniada de assistência médica e odontológica" e "a luta contra o aumento das contribuições dos servidores" (IN 12/2004, BO 10/2004; BO 3/2007; BO 6/2009); "proposta de política de saúde para os servidores do estado de Minas Gerais" (BO 3/2007); esclarecimentos sobre convênios em planos de saúde particulares (BO 6/2009) ou discussões que afetam a saúde dos trabalhadores e formas de prevenção (OP 1/2008).

No Sind-rede/BH as matérias abordam "a definição de uma política de saúde dos servidores e dependentes que garanta a prevenção e o tratamento das principais doenças que atingem a categoria"; "atendimento gratuito nas clínicas"; "construção de hospital do servidor" (BR 02/2007, BR 11/2010). Também tratam do tema em títulos dedicados à defesa da "BEPREM" ou à crítica aos "Planos de Saúde Privados com subsídios da Prefeitura, propostos pela Administração" (JR n $\left.{ }^{\circ} 24,06 / 2010, J_{R}^{\circ}{ }^{\circ} 26,12 / 2010\right)$.

\section{Relações de emprego}

No Sind-UTE/MG se encontram títulos que anunciam a "necessidade de realização de concursos públicos" e que tratam das relações contratuais e da natureza dos contratos de trabalhadores em educação (IN 03, 04, 08, 12/2004; BO 2/2004, IN 16/2007). Particularmente significativas e numerosas são as matérias que discutem a "condição precária dos trabalhadores designados e terceirizados" (IN 1, 2, 12 e 13 de 2004; BO 10, 13/2004; SUB 90/2005; BO 12, 14/2006; IN 16, 17/2007).

No Sind-rede/BH as matérias versam sobre a necessidade de pôr "fim à terceirização" na PBH e de "realização de concursos públicos" (BR 02/2007). 


\section{Condições de trabalho}

No Sind-UTE/MG há matérias que abordam as "Políticas de valorização do magistério" (BO 3/2007); a "necessidade de aumento de quadros nas escolas" (BO13/2004; IN 16/2007); e de "diminuição do número de alunos em sala, do número de classes, da jornada de trabalho". Registra-se também a "defesa do direito a férias prêmio" (IN 8/2004; OP 1/2008; BO 1/2009). Chama a atenção a publicação especial intitulada "A Radiografia da Educação Mineira", que revelou a precariedade das escolas da REEMG na capital e no interior. No documento se lê: "A violência e a falta de condições de trabalho foram mascaradas por um projeto do governo estadual que privilegia algumas escolas, e apenas os bons exemplos nos meios de comunicação" (BO 01/2009).

No Sind-rede/BH se reúnem títulos que versam sobre a falta de condições objetivas para a docência. Uns afirmam a "insuficiência no quadro de profissionais das unidades escolares, principalmente nas que atendem a educação de tempo integral"; outros apontam a necessidade de "munir a escola de estrutura física e humana adequada a portadores de deficiência"; oferecer "condições necessárias para inclusão de alunos e professores com necessidades especiais", e reduzir o "excessivo número de alunos de inclusão por sala" (DA 03/2010, BR 11/2010). Algumas matérias tratam do tempo de trabalho, tais como "calendário de no máximo 200 dias letivos" e "reunião pedagógica dentro da jornada semanal”. (BR 02/2007). Há títulos que apresentam ou relatam eventos promovidos ou apoiados pelo sindicato, sobre relações de poder e trabalho docente. São exemplos o "Seminário dos Servidores Públicos da PBH contra o assédio moral", e o "Seminário sobre Trabalho docente" (JR n 21, de 11/2008). A valorização dos trabalhadores da educação é tema tratado em documentos que se propõem a sensibilizar pais e demais integrantes da comunidade escolar para a importância do trabalho do magistério (Cartilha de 2010).

\section{Organização e relações sindicais}

No Sind-UTE/MG se observam muitas matérias dedicadas à "organização interna" e às "eleições do sindicato" (BO 06, 08/2005/ BO 10,12 /25006; OP 49/2006; BO 02/2007; IN 01, 02/2007; OP50/2007; BO 06, 07/2009). Outras abordam Congressos Estatutários, propostas e teses políticas em disputa (OP 47/2006); a relação com a CNTE (BO 13/2004), a CUT (BO 07/2004), e com organizações sindicais internacionais (OP 49/2006). O mesmo se observa em relação aos "movimentos sociais" e aos "filiados do sindicato" (BO 10/2004). Chamam a atenção as que tratam das "relações com a administração pública estadual" (BO 06/2007) e com os "governos municipais" (OP 48/2006), evi- 
denciando o antagonismo. Há também debates sobre a "reforma sindical" (BO 02/2004); a "repressão ao movimento sindical" (OP 48/2006); discussões sobre o "imposto sindical" (BO 02, 04/2009); a "luta pelo direito à organização" (IN 08/2004) e sobre a "regulamentação do direito de greve" (IN 04, 06/2007).

O Sind-rede/BH aborda a "mobilização dos filiados para atuar ativamente junto ao sindicato", a "filiação de novos sócios", a "convocação para eleições" e a "defesa do sindicato contra medidas da administração que ataquem sua direções e a organização nos locais de trabalho". A "organização interna" e "eleições da diretoria e Conselho Fiscal do sindicato" (BE 11/2009) ou recomposição de vacância na diretoria (BR 02/2010, JR 01/2010) aparecem revelando que a disputa pela direção sindical é grande. Em 2009, as eleições foram disputadas por três chapas. Há temas relacionados aos Representantes de Escolas que se referem a sua convocação, sensibilização ou preparação, como se observa no título "Preparação do Seminário de Representantes" (BR 02/2010, BG 03/2010, JR 01/2010) em que também a pauta de reivindicações da categoria é apresentada e esclarecida. Outros se referem a: necessidade de "liberação de dirigentes sindicais" e "publicação no Diário Oficial do Município (DOM) das liberações sindicais" (BR 02/2007). No Título "File-se ao Sind-rede/BH" apresenta-se a necessidade da aumentar "os recursos financeiros para garantir independência financeira para bancar a luta" (BR 03/2008). Há matérias que se dedicam a divulgar o e-mail e o local no site do sindicato para contatos, que consiste em uma forma de comunicação não presencial entre filiados e diretoria e de divulgação das notícias aos associados (BR 03/2010). Também se evidenciam matérias que versam sobre a relação do sindicato com a CSP-CONLUTAS e com organizações sindicais internacionais $\left(\mathrm{JR} \mathrm{n}^{\circ} 24,06 / 2010\right)$.

\section{Gestão da escola}

No Sind-UTE/MG registram-se matérias sobre os "debates com a comunidade escolar (professores, pais e alunos)"; a exigência de "revisão das dispensas realizadas"; a "institucionalização de concurso público"; a discussão de "critérios para eleições diretas para diretores de escola" (BO 12/2006) e "posse dos diretores eleitos" (IN 06, 08/2004). O modelo de gestão adotado em Minas Gerais é objeto de forte crítica. O tema é tratado no título "O que Aécio fez em Minas não serve para o Brasil" (BO 08/2010). O mesmo informe traz dados sobre os projetos de reajuste salarial. $\mathrm{O}$ tema se repete com a proximidade das eleições presidenciais, como se observa nos títulos "Chega de Choque de Gestão! Vote em quem tem ficha limpa com a educação!"; "Anastasia não cumpre compromissos com os trabalhadores em educação" e "Eleições definem o futuro da Educação no País" (BO 18, 20, 22/2010). 
No Sind-rede/BH constam títulos contendo reivindicações de "garantia de participação democrática, eleições de diretores e coordenadores em cada uma das unidades escolares" e de "transparência nas prestações de contas das verbas destinadas a cada unidade escolar, principalmente às UMEI" bem como "autonomia das UMEI" e "exigências de nomeação e posse de diretoras da Educação infantil eleitas" (BR de 02/2007). Há também denúncias de "quebra de autonomia das escolas" (BG de 03/2010) e matérias que debatem e criticam o modelo único de Regimento Escolar para as Unidades de Educação Infantil apresentado pela SMED, como se pode ler no título "SMED prepara modelo de Regimento Escolar. A quem ele servirá?" (JR n 24, 06/2010). A defesa da democracia extrapola o âmbito da escola em algumas matérias, como no título “Ah, A Praça Ainda é do Povo?”, em que se critica o Decreto no 13.798/2009, que proíbe a realização de eventos de qualquer natureza na Praça da Estação na capital" (BG 23/03/2010).

\section{Política educativa}

No Sind-UTE/MG as matérias versam sobre exigências e propostas de "gestão do sistema" e de "financiamento", a exemplo do que se refere à "participação no seminário sobre o FUNDEB" e à "avaliação da proposta de criação do Fundo" (BO 7/2005, SUB 90/2005; OP 48/2006; OP 50/2007). Há títulos que tratam da "mudança na concepção e na legislação educacional". Como exemplo se pode destacar: a análise da política em curso (OP 01/2008); debates e mobilizações contra as "mudanças na organização curricular do ensino médio" que reduzem o grau das disciplinas obrigatórias (OP 48/2006, BO 02/2009) ou buscam fortalecer disciplinas como filosofia e sociologia (BO 06/2007 e IN 13/2007). Também se observam títulos que se dedicam à defesa da educação pública de qualidade. Isso aparece explicitamente em informes, tais como "Educação e miopia política"; "Sind-UTE/MG convoca mobilização em defesa de concurso público para filosofia, sociologia e ensino religioso"; a perda de conteúdos de fundamentos políticos no currículo; e de quadros docentes qualificados para sua oferta. (IN 15/2004; EE 08-10/2004; PCG 09/2004; BO 03/2005; BO 19/2010). Registram-se também referências à realização de "Conferências de Educação" (IN 15/2007); "avaliação do desempenho docente" (IN 11, BO 13/2004, BO 09/2009A, BO 09/2005); e discussão e contribuições para o "Plano Decenal de Educação/CONAE” (SUB 90/2005, OP 48/2006, BO 02, 04, 07/2009).

No Sind-rede/BH os temas tratados são a "universalização do atendimento na educação infantil" (BR 02/2007), a "defesa da continuidade do atendimento do ensino médio da Rede e a cooperação efetiva entre Estado e Município para garantir os recursos para essa política" (BR 05/2009 e 08/2009). O acompa- 
nhamento do debate nacional e de mudanças na legislação do ensino médio é evidenciado em matérias que também veiculam a ideia de que o debate deve se realizar na PBH. Há divulgação ou informação sobre eventos que discutem as etapas e/ou modalidades da educação, como "Políticas de Educação para Jovens e Adultos" e "Seminário Político-Pedagógico" (BR 12/2009). Temas como mercantilização da educação, qualidade da educação, financiamento da educação, desvalorização do servidor e precarização do ensino público são tratados em textos que abordam tanto a realidade local, quanto a nacional e internacional (CF 08/2009). Algumas matérias se dedicam a criticar a forma de aprovação e conteúdo de novas legislações que implicam consequências consideradas "perversas" para a educação e para o trabalho docente, como aparece nos títulos "O Filho de Dr. Frankestein" e "Entenda melhor alguns problemas da Lei n 9.815/2009" (JR, 01/2010). Alguns títulos criticam a "Lei no 4.689/2010 que aprovou o subsídio como forma de Remuneração dos Trabalhadores da Educação do Estado de Minas Gerais" (JR, nº 24, 06/2010). Há publicações dedicadas exclusivamente à educação infantil, apresentando discussões que vão desde a caracterização da mesma na Rede Municipal de Ensino de Belo Horizonte (RMEBH) até a apresentação de uma concepção de política alternativa para essa etapa da educação básica, que amplie a cobertura e lhe confira qualidade (Manifesto EI, 2010).

\section{Justiça social}

No Sind-UTE/MG se observam matérias que tratam de temáticas amplas respeitantes aos trabalhadores locais e da sociedade tais como: "denúncias sobre corrupção dos meios de comunicação mineiros" (BO 08/2005); "críticas à política econômica", e à "ALCA" (PCG 03/2004). Temas de interesse amplo dos trabalhadores em geral também aparecem em matérias que tratam da "violência no campo", do "latifúndio"; da defesa da "reforma agrária"; do "aumento do salário mínimo" (BO 01/2005); da "crise internacional" (BO 02/2009) e das eleições gerais no país (BO 12/2006). Registram-se ainda distintos tipos de manifestações, tais como a "participação em atos da classe trabalhadora convocados por centrais sindicais", "marchas a Brasília" (BO 10/2007), assim como as que tratam de convocar a participação de todos como "O grito dos excluídos" (BO 10/2004, SUB 90/2005). Também se reúnem matérias sobre a desigualdade racial (PCG 03/2004; OP 48/2006; BO 09/2007) e de gênero (OP 03/2005; BO 02/2007; OP50/2007, OP 01/2008).

No Sind-rede/BH temas amplos envolvendo os trabalhadores também são tratados, tais como "A Crise Mundial" e "A crise econômica e seus efeitos sobre os trabalhadores" (JR n 21, 11/2008). Há "críticas aos resultados da eleição 
para prefeito" que elegeu Márcio Lacerda. Também se reúnem matérias relativas à desigualdade racial (JR n²6, 12/2010), de gênero (BR 03/2008; JR n 21, $11 / 2008, \mathrm{JR} \mathrm{n}^{\circ} 26,12 / 2010$ ) e de solidariedade às lutas de trabalhadores de outros países, como aparece no título "Trabalhador ajuda trabalhador: solidariedade direta ao povo Haitiano" (JR 01/2010). Há informes que se dedicam a divulgar ou relatar eventos de caráter formativo promovidos ou apoiados pelo sindicato, sobre temas diversos, tais como o "Curso sobre Marxismo e Revoluções", os seminários sobre "A Criminalização da Pobreza, das Lutas e Organização dos Trabalhadores", "A Crise Econômica" e o "Fórum Social Mundial Comitê Mineiro" (JR n $\left.{ }^{\circ} 21,11 / 2008\right)$. Alguns títulos tratam de atos públicos envolvendo os trabalhadores do campo e da cidade, apoiados pelo Sind-rede/BH, como o "Ato Público dos Trabalhadores do Campo e da Cidade", o "Ato Contra a Carestia" e o "Ato contra a Violência Sexista" (BR 03/2008; JR n 21, 11/2008).

\section{Manifestações de conflito}

No Sind-UTE/MG se observam dois tipos de caminhos utilizados para a resolução de tensões: a via política e a via jurídica. A primeira é constituída por tentativas de negociações ou pressões, como greves, protestos, assembleias, entre outras. No período estudado se pode encontrar greves longas em que os temas carreira e salário foram as motivações centrais (PCG 05/2004; CEG 08/26, 30/08/2004, BO 04, 06, 07, 09, 10/2004; BO 03, 06 /2005; OP 48/2006; BO 03, 04, 07/2007; BO 12/2008; BO 03, 04/2009; BO 06, 08/2009). O tema "greve" é tratado em vários títulos, sendo usual o registro seguido da evolução do conflito. Uns se dedicam a informar os trabalhadores sobre as decisões. O título "Rede Estadual inicia greve em 08 de abril" registra o meio, a forma de decisão e trata de apresentar as estratégias para a mobilização. Outro exemplo é a matéria: "O Conselho Geral e a Assembléia estadual aprovaram o indicativo de greve e seu início a partir de 08 de abril. Como estratégias de aglutinar forças para a greve definimos assembléias locais ou regionais, que deverão ser realizadas pelas subsedes, assim como as novas reuniões com as comunidades escolares." Ademais, os/as aposentados/as e servidores de superintendências de cada região são chamados para incorporar-se. Os documentos em geral apresentam fotos ilustrativas dos atos. (BO 06/2010). Outros apresentam a "Pauta de reivindicações", como na "campanha salarial educacional 2010" (BO 07/2010). Durante o conflito, as publicações desenvolvem matérias que buscam demonstrar a força do movimento e as tentativas de negociação com o governo Estadual assim como de obtenção de apoio do Ministério da Educação (BO 09, 10, 11/2010). No avanço da greve, as respostas do governo de Minas, como a repressão, ameaças, judicialização do conflito e partidarização são anunciadas em títulos como "Juntos para Avan- 
çar... Não vamos retroceder" que aparecem ao lado de chamadas em defesa do direito de greve e da qualidade da educação em Minas Gerais (BO 12/2010). A via judicial se expressa por meio de ações individuais e/ou coletivas que contam com a mediação do sindicato (BO 02, 04/2004; SUB 90/2005; BO 12/2006; OP 48/2006). Esse tipo de caminho resulta de decisões e benefícios individuais para os envolvidos que podem ser muito prejudiciais para o conjunto dos trabalhadores, por criar situações particulares. Como afirma Rafanhim (2011), o processo de judicialização se verifica nos sindicatos e resulta de promessas contidas nas leis que não se cumprem, assim como de uma aparente fragilidade na organização sindical. Essa opção por tal via para solucionar controvérsias relacionadas à negociação ou supressão de direitos dos trabalhadores não significa necessariamente valorização dos profissionais da educação. Ao contrário, pode representar a negação da efetividade da mobilização.

No Sind-rede/BH se observam também os dois tipos de caminho utilizados pelo Sind-UTE/MG para a resolução de tensões. Quanto à via política, se pode encontrar matérias sobre greves longas em que a carreira e salário foram as motivações principais. As matérias se dedicam a explicitar os motivos, as reivindicações, o calendário de atividades e/ou histórico da greve (BR 08/2009, BE 03/2010, DA 03/2010, BG 04/03/2010, 16/03/2010, JR 01/2010, BG 24/03/2010, BG e 29/03/2010, JR n ${ }^{\circ} 24,06 / 2010$ ). Chama a atenção a recorrência de títulos referidos às reivindicações de "equiparação da carreira de educador infantil com a de professor municipal". Há também matérias dedicadas a esclarecer os leitores sobre o direito de greve e seu exercício durante o estágio probatório e informam sobre "manifestações, abaixo-assinados e pressões para garantir a participação das educadoras infantis nas direções de escolas" (BR 03/2008). Algumas divulgam atos públicos "contra a política educacional" do município (DA 03/2010). Há também títulos que se referem a lutas mais amplas dos trabalhadores da educação no país, tais como "Em greve pelo Brasil" (BG de 03/2010) e "Manifesto Nacional: 14 de março greve nacional da educação" (BR 03/2008). Observam-se estratégias de pressão a órgãos do poder público para a defesa da educação, como se evidencia no expediente enviado à Promotoria da Infância e Juventude, colocando-a a par da situação e solicitando-lhe "ajuda para solucionar [...] fatos desenvolvidos pela Administração Municipal que ferem os direitos das crianças e adolescentes" (DA 03/2009). O recurso à via judicial se expressa em matérias que se referem a juízos por "recusa de diploma de conclusão de cursos de pós-graduação para progressão" (JR 01/2010). Há também expressões de estratégias políticas, como atesta a coleta de assinaturas de apoio ao "Projeto de Lei de Iniciativa Popular, acerca de progressão na carreira, piso salarial e unificação das carreiras de educador infantil com a de professor municipal” (BR 08/2009). 


\section{Considerações finais}

Este estudo evidencia claramente a heterogeneidade das organizações sindicais estudadas, haja vista as diferentes histórias, estruturas, formas de organização, vinculações, relações com base e patronato, entre outras de suas características. Revela também as tensões presentes nas políticas educativas, no trabalho docente, na organização dos trabalhadores, bem como os desafios postos para cada um desses campos.

A diversidade temática identificada nas publicações dos sindicatos pesquisados demonstra também o variado e complexo campo de atenção e/ou atuação que essas organizações buscam contemplar em seu cotidiano. A análise dos discursos contidos nas publicações revela a existência de significativas diferenças e proximidades entre esses sindicatos.

O Sind-UTE/MG aparece em sua luta radicalizada em torno da questão salarial e profissional, e mais precisamente pelo cumprimento do Piso e pela carreira docente na REEMG. A radicalização do Sind-UTE/MG encontra como resposta estatal uma igual radicalidade, expressa na reiterada negativa às reivindicações, judicialização e criminalização do conflito. Nesse contexto, as perspectivas de mudanças para o futuro próximo parecem ser reduzidas e há indícios de continuidade da radicalidade do conflito. O Sind-rede/BH, por sua vez, surge em meio a uma luta radicalizada no interior do próprio Sind-UTE/ MG, tendo a ruptura como a saída. De um lado, experimenta o desenvolvimento de uma política sindical distinta, outra forma de organização e relação com as bases, referenciada na organização por local de trabalho e estabelecimento de outros vínculos em relação a centrais sindicais e organizações internacionais. Por outro lado, enfrenta o desafio de consolidar sua proposta política sindical e efetivar e manter a organização da base. Embora as reivindicações prioritárias sejam igualmente em torno das questões salariais e profissionais da categoria, o tema central da luta da categoria nos últimos anos se apresenta localizado na superação da segmentação da carreira dos professores e educadores infantis e na universalização da educação infantil. No plano mais amplo, aposta na luta de classe pela transformação da sociedade. Tal como ocorre com o Sind-UTE/MG, a radicalização do Sind-rede/BH encontra a radical resposta estatal, também expressa na reiterada negativa às reivindicações, na judicialização e criminalização do conflito por parte da PBH. Considerando que entre as prioridades do governo municipal recém-reeleito a educação pública ocupa lugar secundário, as perspectivas de mudanças na RMEBH também parecem ser reduzidas para o futuro próximo e a continuidade da radicalidade do conflito docente tende a perdurar. 


\section{REFERENCIAS}

RAFANHIM, L. Processo de judicialização dos sindicatos e valorização do magistério. Trabalho apresentado no I Encontro Luso-Brasileiro Sobre o Trabalho Docente/VI Encontro Brasileiro da Rede Estrado. UFAL, Maceió, nov. 2011.

\section{Sites consultados}

SindUTE. Sindicato Único dos Trabalhadores em Educação de Minas Gerais. Disponível em: <http://www.sindutemg.org.br/novosite/index.php>. Acesso em: 10/06/2012.

SindREDE/BH. Sindicato dos Trabalhadores em Educação da Rede Pública Municipal de Belo Horizonte. Disponível em: <http://www.redebh.com.br/>. Acesso em: 10/06/2012.

CSP-CONLUTAS. Central Sindical Popular. Disponível em: <http://cspconlutas.org. br/>. Acesso em: 10/06/2012.

Texto recebido em 20 de outubro de 2012.

Texto aprovado em 05 de novembro de 2012. 